\title{
Fetal Neurology: The Role of Fetal Stress
}

\author{
Aida Salihagić Kadić
}

\begin{abstract}
Fetal development and growth, as well as the timing of birth is influenced by the intrauterine environment. Many environmental factors causing the fetal stress can interfere with fetal development and leave long-term and profound consequences on health. Fetal glucocorticoid overexposure has primarily significant consequences for the development of the central nervous system. In response to an adverse intrauterine conditions, the fetus is able to adapt its physiology to promote survival. However, these adaptations can result in permanent changes in tissue and organ structure and function that directly 'program' predisposition to disease. Cardiometabolic disorders, behavioral alterations and neuropsychiatric impairments in adulthood and/ or childhood may have their roots in the fetal period of life. Fetal response to stress and its prenatal and lifelong consequences are discussed in this review.
\end{abstract}

Keywords: Fetal neurology, Fetal stress, Fetal behavior, Consequences of fetal stress.

How to cite this article: Kadić AS. Fetal Neurology: The Role of Fetal Stress. Donald School J Ultrasound Obstet Gynecol 2015;9(1):30-39.

Source of support: This work was supported by a grant from University of Zagreb.

Conflict of interest: None declared.

\section{INTRODUCTION}

The fetus needs physiological, stress-free environment for its normal growth and development. Overall fetal development can be regarded as a trade off between growth opportunity and mortality risk in the developmental environment. Physiological sensors compute this trade of as a function of energy balance and environmental stress and effectors initiate physiological, developmental and behavioral responses. ${ }^{1}$ A large number of factors can alter the intrauterine environment and lead to fetal stress. Maternal undernutrition or placental insufficiency, maternal emotional stress or stressful life events, as well as fetal pain may trigger the fetal stress response. ${ }^{2} \mathrm{~A}$ high serum level of fetal stress hormones has been found in pregnancies with intrauterine growth restriction (IUGR). ${ }^{3}$

Professor

Department of Physiology, School of Medicine, University of Zagreb, Zagreb, Croatia

Corresponding Author: Aida Salihagić Kadić, Professor Department of Physiology, School of Medicine, University of Zagreb Salata 3, 10000 Zagreb, Croatia, Phone: 0038514566763, e-mail: asalih@mef.hr
Fetal exposure to stress affects neurodevelopment, as well as the development of many organs and organ systems, and has lifelong consequences.

\section{FETAL STRESS AND ITS EFFECTS ON BEHAVIOR}

All behavior is the result of the brain function. Up to now it has been unknown how the brain marshals its millions of individual nerve cells to produce behavior and how these cells are affected by the environment. ${ }^{4}$ Altough the brain function still remains shrouded in a veil of mystery, it has been well known that over $99 \%$ of the human neocortex is produced during the fetal period. ${ }^{5}$ Owing to the employment of state-of-the-art methods and techniques, such as $4 \mathrm{D}$ sonography in prenatal investigations, an growing pool of information on the functional development of the central nervous system (CNS) and fetal behavioral patterns has been made available. ${ }^{2}$ Fetal behavior, defined as any fetal activity observed or recorded with ultrasonic equipmment, reflects developmental and maturational processes of the CNS. ${ }^{6}$ The aim of the following sections to illustrate a brief overview of fetal behavior and to answer the question how stress affects some of fetal activities, as well as to present its consequences on the brain structure and function.

\section{Prenatal Neuromotor Development and Fetal Stress}

Fetal development is dependent on fetal physical activity. One of the prerequisites for the first embryonic movements is the existence of the earliest interneuronal connections, the synapses. They can be detected in the spinal cord shortly before the onset of embryonic motility, at 6 to 7 weeks of gestation. ${ }^{7}$ Therefore, the neural activity leading to the first detectable vermicular movements at 7 to 7.5 weeks is considered to originate from the spinal motoneurons. ${ }^{8}$ Simultaneously with the onset of spontaneous movements, the earliest motor reflex activity appears, indicating the existence of the first afferentefferent circuits in the spinal cord. ${ }^{9}$ General movements can be recognized from 8 weeks onward. This earliest complex, well-organized movement pattern, which include the head, trunk and limb movements, has been interpreted as the first sign of a supraspinal control on motor activity. ${ }^{10,11}$ 
As the medulla matures in advance of more rostral structures of the brain stem, reflexive movements of the head, body, extremities, as well as breathing-like movements and alterations in heart rate, appear in advance of other functions, at 9 to 10 weeks. ${ }^{11}$ Facial movements, which are also controlled by cranial nerves V and VII, appear around 10 to 11 weeks. From 10 weeks onward, the number and frequency of fetal movements increase and the repertoire of movements begins to expand. ${ }^{2}$

At 10 weeks of gestation the fetus begins to show the earliest signs of right- or left-handed behavior. Stimulation of the brain influences its organization and fetal motor activity induces the brain to develop 'handedness' and subsequent lateralization of the function. ${ }^{12,13}$ Prenatal stress in the second and third trimesters can cause child mixed handedness. A high level of maternal distress and stressful life events lead to a three- to four-fold higher prevalence of child mixed-handedness at 3.6 years of age. ${ }^{14}$ It reflects reduced asymmetry in hemispheric motor representation ${ }^{15}$ and can be a marker of deviant brain development. Mixed handedness is common characteristic of attention deficit hyperactivity disorder (ADHD), schizophrenia, autism and there is growing pull of evidence that prenatal stress may increase the risk for these diseases. ${ }^{16}$

From 13 gestational weeks onwards, the fetus performs goal oriented hand movements and a target point can be recognized for each hand movement. ${ }^{17}$ At 13 to 14 weeks, the fetus begins to perform isolated finger movements. 18

Our longitudinal study, performed by 4D ultrasound, has shown increasing frequency of general movements, isolated arm and leg movements, stretching, as well as head movements, during the first trimester of normal pregnancie. ${ }^{19}$ General movements are the most frequent movement pattern in this period of gestation. ${ }^{20}$

In the second trimester, the brainstem continues its maturation, causing an increase in the range and complexity of the behavioral patterns. Between 16 and 18 weeks, eye movements appear as a result of the midbrain maturation. ${ }^{2}$ The second half of pregnancy is characterized by gradual organization of fetal movement patterns. The periods of fetal quiescence begin to increase, and the rest-activity cycles become recognizable. According to our results, the most frequent facial movement patterns in the second trimester were isolated eye blinking pattern, grimacing, sucking and swallowing. ${ }^{19}$

At the beginning of the third trimester, evoked potentials can be registered from the cerebral cortex, indicating that the functional connection between periphery and cortex operates from that time onward. ${ }^{21}$ Important processes occur in the cortex including the cortical areal differentiation and lamination of the neocortex. ${ }^{22,23}$ However, the cerebral cortex is still very immature and until delivery, subunits of the brainstem remain the main regulators of all fetal behavioral patterns. ${ }^{11}$ Increasing complexity of general and facial movements and reduction or stagnation of their frequency, ${ }^{19}$ as well as appearance of sleep-wakefulness patterns in EEG at 30 weeks of gestation are the consequence of the brainstem maturation. It is interesting to note that the fetus and neonate display similar wake-sleep cycles, ${ }^{24}$ which can be disturbed by prenatal stress. ${ }^{25}$ Furthermore, our studies have demonstrated that prenatal-neonatal continuity exists even in subtle, fine movements such as facial mimics. ${ }^{26,27}$

The diverse repertoire of fetal movements raises the question of their function and significance for normal, physiologic development of the fetus. There is a growing pool of evidence that fetal motor activity is fundamental for the development of most parts of the nervous system and the muscles. ${ }^{2}$ It has been also shown that fetal motor activity and behavior may be influenced by a number of external factors (Table 1). Injection of corticosteroids for fetal lung maturation, maternal emotional stress, maternal diabetes mellitus, fetal anencephaly and IUGR cause quantitative or qualitative changes of fetal spontaneous movements and behavioral activity. ${ }^{2}$

A new prenatal neurologic scoring test based on evaluation of fetal spontaneous motor activity using four-dimensional (4D) ultrasound, named KANET (the Kurjak Antenatal Neurodevelopmental Test), ${ }^{28}$ was applied in 5 growth restricted fetuses. ${ }^{29}$ As already mentioned, increased fetal cortisol levels are found in IUGR pregnancies, ${ }^{3}$ indicating raised endogenous glucocorticoids as mediators of growth restriction. The results of our case study have shown that KANET has potential in recognizing pathologic and borderline behavior in IUGR fetuses with or without blood flow redistribution toward the fetal brain.

KANET score for the fetus from the case 1 which also had severe hypoxia is demonstrated in Table 2. Repertoire of fetal movements was very deficient, the quality and quantity of movements were significantly altered. The fetus had neurological thumb, general movements were abnormal, fetal face was like a mask (Fig. 1). ${ }^{29}$ On the other hand, an increased frequency of yawning has

Table 1: Influence of external factors on fetal general movements and behavioral activity (references are given in the text)

\begin{tabular}{ll}
\hline Quantitative changes & Qualitative changes \\
\hline - Cigarette smoking & • Maternal diabetes mellitus \\
- Corticosteroids & - Fetal cerebral impairment \\
- Oligohydramnion & • Fetal anencephaly \\
- Maternal emotional stress & - IUGR \\
\hline
\end{tabular}


Table 2: KANET score in IUGR fetus ${ }^{28}$

\begin{tabular}{|c|c|c|c|c|}
\hline \multirow[b]{2}{*}{ Sign } & \multicolumn{3}{|c|}{ Score } & \multirow[b]{2}{*}{ Sign score } \\
\hline & 0 & 1 & 2 & \\
\hline Isolated head anteflexion & Abrupt & $\begin{array}{l}\text { Small range } \\
\text { (0-3 times of } \\
\text { movements) }\end{array}$ & $\begin{array}{l}\text { Variable in full range, many } \\
\text { alternation ( }>3 \text { times of } \\
\text { movements) }\end{array}$ & 0 \\
\hline $\begin{array}{l}\text { Cranial sutures and head } \\
\text { circumference }\end{array}$ & $\begin{array}{l}\text { Overlapping of } \\
\text { cranial sutures }\end{array}$ & $\begin{array}{l}\text { Normal cranial sutures } \\
\text { with measurement of } \\
\text { head circumference } \\
\text { below the normal limit } \\
(-2 S D) \text { according to } \\
\text { gestational age }\end{array}$ & $\begin{array}{l}\text { Normal cranial sutures with } \\
\text { normal measurement of head } \\
\text { circumference according to } \\
\text { gestational age }\end{array}$ & 0 \\
\hline Isolated eye blinking & Rare or absent & $\begin{array}{l}\text { Not fluent ( } 0-5 \text { times of } \\
\text { blinking) }\end{array}$ & $\begin{array}{l}\text { Fluency ( }>5 \text { times of } \\
\text { blinking) }\end{array}$ & 0 \\
\hline $\begin{array}{l}\text { Facial alteration } \\
\text { (grimace or tongue } \\
\text { expulsion) }\end{array}$ & Rare or absent & $\begin{array}{l}\text { Not fluent ( } 0-5 \text { times of } \\
\text { alteration) }\end{array}$ & $\begin{array}{l}\text { Fluency ( }>5 \text { times of } \\
\text { alteration) }\end{array}$ & 0 \\
\hline $\begin{array}{l}\text { Mouth opening } \\
\text { (yawning or mouthing) }\end{array}$ & Rare or absent & $\begin{array}{l}\text { Not fluent ( } 1-5 \text { times of } \\
\text { alteration) }\end{array}$ & $\begin{array}{l}\text { Fluency (> } 5 \text { times of } \\
\text { alteration) }\end{array}$ & 1 \\
\hline Isolated hand movement & Cramped & Poor repertoire & Variable and complex & 1 \\
\hline Isolated leg movement & Cramped & Poor repertoire & Variable and complex & 0 \\
\hline Hand to face movements & Abrupt & $\begin{array}{l}\text { Small range ( } 0-5 \text { times } \\
\text { of movement) }\end{array}$ & $\begin{array}{l}\text { Variable in full range, many } \\
\text { alternation ( }>6 \text { times of } \\
\text { movements) }\end{array}$ & 0 \\
\hline Fingers movements & $\begin{array}{l}\text { Unilateral or bilateral } \\
\text { clenched fist, } \\
\text { (neurological thumb) }\end{array}$ & $\begin{array}{l}\text { Cramped, invariable } \\
\text { finger movements }\end{array}$ & $\begin{array}{l}\text { Smooth and complex, } \\
\text { variable finger movements }\end{array}$ & 0 \\
\hline \multirow[t]{2}{*}{$\begin{array}{l}\text { Gestalt perception of general } \\
\text { movements }\end{array}$} & Definitely abnormal & Borderline & Normal & 0 \\
\hline & & & Total score & 2 \\
\hline
\end{tabular}

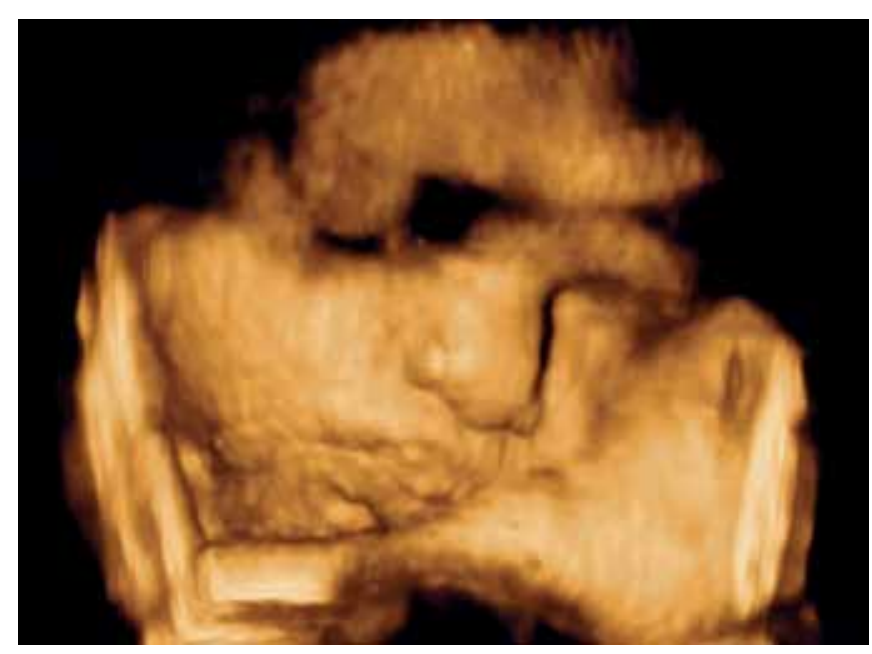

Fig. 1: Fetal face without changes of facial expressions during 30 minutes of examination using 4D ultrasound

been reported in fetuses suffering hypoxia and growth restriction, as well as severe anemia. It was interpreted as a fetal attempt to increase the venous return and in that way improve the delivery of oxygenated blood to the vital organs. ${ }^{30}$

Specialized movement patterns, such as swallowing and breathing-like movements, develop, mature and play an important role during intrauterine life.

Fetal breathing-like movements appear at 10 weeks of gestation. Changes in their frequency and complexity during pregnancy are consequences of the maturation of the fetal lungs as well as the respiratory and sleep centers in the CNS. ${ }^{11}$ These movements are crucial for the normal lung development as well the development of respiratory muscles. Betamethasone, maternal hyperglycemia and hypercapnia are responsible for an increase in frequency of breathing-like movements, whereas fetal hypoxia, maternal consumption of alcohol and cigarette smoking decrease the incidence of these movements. ${ }^{2}$

Swallowing is one of the favorite activities of the fetus. It contributes to the regulation of the amniotic fluid volume, the development and maturation of the fetal gastrointestinal tract and to the fetal somatic growth. ${ }^{31}$ This fetal activity was observed as early as 11 weeks of gestation, ${ }^{32}$ with daily swallowing rates of 500-1000 ml near term. ${ }^{33}$ Prenatal swallowing is influenced by fetal hypoxia, hypotension, plasma osmolarity changes and the volume of amniotic fluid. ${ }^{33}$

\section{Prenatal Neurosensory Development and Fetal Stress}

Normal intrauterine milieu provides an optimal, stimulating and interactive environment necessary for fetal development. Touch and pain are among the first senses to be developed during intrauterine life. Twin pregnancies 
allow to observe the first reactions to touch in utero. Perioral region, hands, lower limbs become touch sensitive at 7.5, 10.5 and 14 weeks of gestation, respectively (for review, see reference 2). Thalamocortical pathways, important for the perception of sensory impulses, reach the somatosensory cortex between 22 nd and 26th week of gestation. ${ }^{34}$

The first nociceptors appear at 7 weeks of gestation, and by the 20th week these are present all over the body. ${ }^{35}$ Sensing pain requires a develop neural pain system. Higher parts of pain pathways include the spinothalamic tract, established at 20 weeks and myelinated by 29 weeks of gestation, and thalamocortical connections, which begin to appear into the cortex at 24 to 26 weeks. After 26 weeks, the fetus has the necessary connections to sense pain. At 29 weeks, somatosensory evoked potentials become detectable and they may provide evidence of pain processing in the somatosensory cortex. ${ }^{35}$

The earliest reactions to painful stimuli are motor reflexes, resembling withdrawal reflexes. They can be detected at 7.5 weeks of gestation. As early as 16 to 18 weeks, fetal cerebral blood flow increases during invasive procedures. ${ }^{36}$ An elevation of noradrenaline, cortisol, and beta-endorphin plasma levels, in response to needle pricking of the innervated hepatic vein for intrauterine transfusion, was registered in a 23-week-old fetus. Pricking of the noninnervated placental cord insertion for the same purpose had no effect. ${ }^{37,38}$ Obviously, painful stimuli trigger a wide spectrum of reactions, such as activation of the hypothalamo-hypophysial axis or autonomic nervous system, without reaching the cortex. In premature neonates born after the 28th gestational week, the most promising pain indicators are changes in facial activity, shifts in infant sleep/wake state, and physiological changes of heart rate and blood oxygen saturation. ${ }^{39,40}$ It is important to point out that the hormonal, autonomic, and metabolic responses to painful stimuli can be suppressed by analgesics. ${ }^{36,41}$

One of the most important effects of a painful experience is the prolonged stress response. ${ }^{42}$ This includes marked fluctuations in blood pressure, cerebral blood flow and hypoxemia, which may predispose to intracranial hemorrhage. ${ }^{36}$ Furthermore, animal experiments have indicated that elevated cortisol levels, equivalent to those secreted during the stress response in humans, are associated with fetal brain damage. ${ }^{43}$ Fetal responses to painful stimuli can cause both short and long-term changes in the CNS. Long-term follow-up studies of infants treated in intensive care units and exposed to pain and/or stress have demonstrated correlations between the length of stay in the intensive care unit and altered pain thresholds as well as abnormal pain-related behavior later in life. ${ }^{42,44}$ Even a short-term painful experience, such as neonatal circumcision without analgesia, was shown to intensify subsequent painrelated behavior (following vaccination 4 to 6 months later) in comparison with the findings in noncircumcised infants. ${ }^{45}$ All of these findings underline the importance of stress-free environment for the normal physiologic and psychologic development of the fetus and the neonate. Thus, from a clinical perspective, the findings that harmful stress responses and their sequelae can be prevented by adequate pain treatment $\mathrm{t}^{41,46}$ are extremely important.

The fetus lives, not only in a stimulating matrix of motion, tactile sensations, but also of sound. It has been shown that the fetus can register and react to exogenous acoustic stimulation and that the character of fetal reactions changes as the pregnancy progresses. ${ }^{47}$ Cochlear function develops between 22 and 25 weeks of gestation, and its maturation continues during the first 6 months after delivery. Fetal reactions to very loud sounds have been detected from 26 weeks onwards. Delayed selective response to sounds can be explained by the prolonged pontine maturation. During the last weeks of pregnancy (from the 36th week onwards), the fetus responds to external noise, even to the sound of mother's voice, with reflexive body movements, head-turning and heart-rate acceleration. But even more astonishing finding is that the fetus at this age is able not only to perceive the sounds, but also to discriminate between different sounds. Furthermore, the fetus displays the selective preference for mother's voice or other familiar voices. These findings are explained by the tonotopic organization of the cochlear nuclei and by the maturation of the brain stem during the last weeks of pregnancy. ${ }^{11}$ These findings also indicate that the brainstem displays learning-related activity. Fetuses less than 37 weeks of gestation of mothers who smoke throughout pregnancy, have a delayed onset of response to the maternal voice. ${ }^{48}$ It is interesting that if the mother does not speak, a newborn may be 2 months delayed in development of the tonotopic column and less able to discern intensity, rhythm, and shape of each sound. Growth restriction could also affect the development of auditory perception in human fetuses. ${ }^{49}$

Taste buds are developed by the 7th week of gestation. ${ }^{50}$ By swallowing of amniotic fluid the fetus also explores a wide variety of tastes. It has been shown that fetal swallowing increases with sweet taste and decreases with bitter or sour tastes. ${ }^{51}$ Hence, sweet taste is already in utero the favorite taste. The main feeding regulatory factors, neuropeptide Y (NPY) and leptin, are secreted in the human fetuses as early as 16 and 18 weeks, respectively. ${ }^{2}$ NPY is the most potent known inducer of food intake and a leptin is a primary satiety 
factor. Contrary to its function in adults, leptin does not suppress fetal ingestive behavior and stimulates fetal swallowing. The lack of leptin-inhibitory responses might potentiate feeding and facilitate weight gain in newborns, despite high body fat levels. Recent studies have also shown that an adverse intrauterine environment, with altered fetal orexic factors, and exposure to over or undernutrition can lead to disturbance of appetite regulation and the development of obesity in childhood and/or adulthood. ${ }^{52,53}$ Maternal bereavement during the prenatal period was associated with increased risk of overweight or obesity in young male offsprings and this may possibly be reflected to severe stress exposure early in life. ${ }^{53}$

\section{NEUROENDOCRINE RESPONSE OF THE FETUS TO STRESS}

The primary role of stress is the protection of organism. Many adaptive changes induced by fetal stress increase the chance of fetal survival by creating a short-term protection. However, these changes can leave profound alterations in the structure and functions of the organism. ${ }^{2}$

The neuroendocrine stress axis includes the production and secretion of the corticotropin releasing hormone $(\mathrm{CRH})$, adrenocorticotropic hormone $(\mathrm{ACTH})$ and cortisol. Stress stimulates the hypothalamus to release $\mathrm{CRH}$ into the hypophysial portal system causing a release of $\mathrm{ACTH}$ into the peripheral blood circulation. ACTH stimulates secretion of glucocorticoid hormone, cortisol, from the adrenal glands. This axis operates in the fetus from midgestation. ${ }^{54}$ Fetal CRH influences the timing of birth. It means that the fetus has an active role in the initiation of parturition. It has been well known that prenatal stress is associated with an increased risk of preterm delivery. ${ }^{55,56}$ Further, fetal ACTH has a negative influence on motor functions, impairing motor coordination and muscle tonicity. ${ }^{2}$ It also reduces attention span, and increases irritability. Epidemiological and experimental investigations have shown that chronic overexposure to endogenous or exogenous glucocorticoids during intrauterine life has long-term adverse effects on health. ${ }^{43,57-59}$ It has been established that cortisol, which accelerates lung maturation and enables survival of premature infants, may have a negative influence on growth and development of the lungs, and even on the growth of the whole organism. ${ }^{60}$ Recent study has indicated that overexposure to glucocorticoids can result in premature cessation of fetal cell proliferation, leading to fetal growth restriction. ${ }^{61}$ Low birth weight is a marker of an adverse intrauterine environment and prenatal stress. ${ }^{62}$ Further, cortisol stimulates maturation of the brain. However, accelerated brain maturation is associated with the structural as well as behavioral changes. Stress induces structural changes of the hippocampus ${ }^{43,57-59}$ that are associated with memory impairment and learning disabilities later in life. According to experimental data, structural changes of the hippocampus include decreased number of neurons and corticosteroid receptors, decreased level of serotonin, and decreased synaptic density on distinct regions of the hippocampus. Hippocampus and parahippocampal areas, which have the largest concentrations of cortisol and $\mathrm{CRH}$ receptors, ${ }^{63}$ are the most vulnerable CNS sites to stress. ${ }^{64}$ Behavioral changes associated with accelerated maturation of the brain include hyperalertness and impaired fetal responsiveness to novel stimuli possibly due to the effects of CRH and stress hormones. ${ }^{65}$ It is important to point out that fetal and maternal cortisol stimulate $\mathrm{CRH}$ production in the placenta and a positive feedback loop allows a simultaneous rise in cortisol and CRH. ${ }^{66,67}$ A high serum level of these hormones has been found in pregnancies with IUGR, ${ }^{3}$ pre-eclampsia, ${ }^{68}$ bacterial infectious disease, ${ }^{69}$ diabetes and twin pregnancies. $^{70}$

\section{LIFELONG CONSEQUENCES OF FETAL STRESS}

Stress hormones, according to animal studies, may reduce the brain growth, ${ }^{71,72}$ delay the axon myelisation and influence neural cell replication, differentiation ${ }^{73,74}$ as well as neuron maturation and synaptic stabilization. ${ }^{75,76}$ A single injection of glucocorticoid resulted in a dosedepended neural degeneration of pyramidal hippocampal neurons in rhesus monkeys ${ }^{43}$ and a reduction of $30 \%$ in hippocampal volume was found 20 months postpartum. ${ }^{77}$ In prenatal stressed primates a shorter attention span, ${ }^{78}$ a stronger emotional reaction to stress ${ }^{79}$ and lower levels of exploratory behavior ${ }^{80}$ have been observed. In human investigations, prenatal stress has been associated with profound impairment of hippocampal functioning 81 and impaired neurodevelopment in early life. ${ }^{62}$ Human studies have also shown that long-term neurodevelopmental effects of prenatal stress include a wide spectrum of disorders and disturbances. Attention deficit hyperactivity disorder, ${ }^{82}$ sleep disturbances, unsociable and inconsiderate behavior, as well as psychiatric disorders, including schizophrenic episodes, depressive and neurotic symptoms, drug abuse, mood, and anxiety, ${ }^{81}$ can be recognized in children exposed to stress during intrauterine life. Increased maternal stress during pregnancy seems to influence infant temperament and cognitive functions ${ }^{83-85}$ and adversely influences the child's learning and the memory at age six. ${ }^{86}$ There is also evidence that severe maternal stress is associated not only with lower childhood cognitive abilities, but also 
with language abilities at $5 \frac{1}{1} 2$ years of age. ${ }^{87}$ Fortunately, many investigations have shown that increased maternal care and environmental enrichment can compensate for prenatal stress-induced effects. ${ }^{88-90}$ Recent study has also indicated that infant cognitive development can be moderated by infant-mother attachment. ${ }^{85}$

There are data showing associations between maternal stressful life events and an increased risk of certain birth defects, such as cleft palate, cleft lip with or without cleft palate, d-transposition of the great arteries, and tetralogy of Fallot. ${ }^{91}$ According to recent investigation, prenatal exposure to severe emotional stress may slightly increase the prevalence of congenital heart defects in offspring. ${ }^{92}$ Prenatal stress may also increase the susceptibility to childhood cancer by affecting immune responses and hormonal balance. Severe antenatal stress following maternal bereavement, especially due to loss of a child or a spouse, is associated with an increased risk of certain childhood cancers in the offspring, such as hepatic cancer and non-Hodgkin disease, but not with childhood cancer in general. ${ }^{93}$

The underlying etiology of many chronic diseases, such as hypertension, diabetes and coronary heart disease, has been traced in intrauterine environment. ${ }^{94}$ The explanation for these diseases should be sought in the hyper-responsive neuroendocrine stress axis, which includes magnified or prolonged responses of $\mathrm{CRH}$ and cortisol to acute stressors. Changes in hormonal stress axis cause metabolic dysfunctions. Further, prenatal glucocorticoid excess can alter the development of CNS feeding centers, resulting in hyperphagia and obesity in childhood and/or adulthood. Fetal overexposure to glucocorticoids is also associated with a permanent reduction in nephron number and hypersensitivity to the effects of vasoconstrictors, leading to disturbance of blood pressure regulation. ${ }^{95}$ Obviously, the early survival benefits come at a cost and some of the most common diseases of the modern society may have their origins in the fetal period of life.

The adaptive changes made by the fetus in response to suboptimal condition of the intrauterine environment result in permanent changes not only in metabolism, but also in structure and function of organs and organ systems. ${ }^{96}$ This phenomenon is termed early life programming or developmental programming. Programming by early life stress of hypothalamic-pituitary-adrenal (HPA) axis results in reduced expression of glucocorticoid receptors (GR) in the hippocampus leading to a loss of feedback inhibition and an overactive HPA axis, both in the basal state and under conditions of stress. Chronic mild glucocorticoid excess can produce adverse metabolic, cardiovascular and neuropsychiatric effects. ${ }^{96}$ Fascinat- ingly, high level of postnatal care and maternal care increase expression of GR receptors in the hippocampus, resulting in elimination of the effects in programming of HPA axis. ${ }^{96}$ That is the result of activation of the serotoninergic pathways in response to tactile stimulation. ${ }^{97}$

The placenta has a key role in some forms of programming. A perturbed maternal environment, due to poor diet, excessive stress or impaired health during pregnancy, disturbs placental function and thus delivery of nutrients and oxygen to the fetus (for references, see reference 96). The activity of placental enzyme, 11 $\beta$-hydroxysteroid dehydrogenase type 2 (11 beta-HSD2) which converts active glucocorticoids into inactive products and provides a barrier to maternal glucocorticoids, is reduced. Administration of exogenous glucocorticoids reduces also the activity of the enzyme 11 beta-HSD2, decreasing this barrier to excess glucocorticoids and reducing fetal growth. The fetus is able to adapt in response to stressors, altering tissue size, structure and function, in order to promote survival. These adaptation, although beneficial in the short term, when conflicted by postnatal conditions predispose to an increased risk of adult diseases, such as cardiovascular disease, type 2 diabetes, psychiatric disorders, obesity. ${ }^{96}$ Furthermore, recent studies have indicated that high maternal cortisol in pregnancy and/ or inhibition of 11 beta-HSD2 are associated with programmed outcomes in childhood including higher blood pressure, behavioral disorders as well as altered brain structure. ${ }^{61,98}$ Reduced placental HSD2 activity, estimated from measurements of cord blood cortisol and cortisone, is associated with higher blood pressure aged 3 years. ${ }^{99}$ Recent studies in both humans and experimental animal models have also highlighted in particular a range of behavioral and cognitive impairments arising from inhibition of 11 beta-HSD2 and glucocorticoid overexposure during prenatal development. ${ }^{98}$

Programming and fetal stress may affect males and females differently. It has been shown that in human pregnancies the placenta of female fetuses may impart a relative protection from glucocorticoid excess due to increased glucocorticoid inactivation compared with males. ${ }^{100}$ Indeed, levels of HSD2 increase through gestation $^{101}$ and there is sex-differences in placental function and the activity of this enzyme. ${ }^{100}$ Prenatal exposure to stress is associated with a higher risk of depressive symptoms, ${ }^{102}$ schizophrenia, ${ }^{103}$ ADHD in boys then in girls. ${ }^{104}$ On the other hand, the high level of maternal cortisol in early pregnancy, but not in late gestation, is associated with more affective problems in girls (they had a larger right amygdale volume measured by MRI; the amygdale is important for emotional memory processing). ${ }^{105}$ It has been also shown that diet induced alterations in 
intrarenal renin-angiotensin system occur in male fetuses rather than females, leading to the postulate that gender-based sensitivity to nutrient deficit likely reflects differences between trajectories of growth, development and caloric demand in male and female fetuses. ${ }^{106}$ Furthermore, gender differences may cross generations. Experimental data have shown that maternal protein restriction adversely impacts glucose and insulin metabolism of male and female second-generation offspring in a manner specific to gender and the developmental time window. ${ }^{107}$ According to recent data programmed outcomes are more evident in male than female offspring, ${ }^{108}$ including programmed outcomes due to excess in utero glucocorticoid exposure. ${ }^{109}$

\section{CONCLUSION}

Prenatal stress can interfere with the fetal neurodevelopment and leave the long-term and profound consequences on the brain structure and function. Fetal exposure to stress also affects the development of many other organs and organ systems, and has lifelong consequences. There are recent data showing gender differences in vulnerability to prenatal stress. Finally, stress-free intrauterine environment is crucial for normal prenatal and postnatal growth and development, as well as good health later in life. Prevention of certain diseases in childhood as well as some chronic diseases in adulthood should start even before birth! Understanding the prenatal influences on child and adult diseases and developing of preventive strategies for pregnancies at risk is one of the major challenges of biomedical research and perinatal medicine.

\section{REFERENCES}

1. Crespi EJ, Denver RJ. Ancient origins of human developmental plasticity. A J Human Biol 2005;17(1):44-54.

2. Salihagić Kadić A, Predojević M, Kurjak A. Advances in fetal neurophysology. In: Pooh RK, Kurjak A, editors. Fetal neurology. New Delhi: Jaypee Brothers Medical Publishers 2009;161-221.

3. Golland RS, Jozak S, Warren WB, Conwell IM, Stark RI, Tropper PJ. Elevated levels of umbilical cord plasma corticotropin-releasing hormone in growth-retarded fetuses. J Clin Endocrinol Metab 1993;77(5):1174-1179.

4. Kandel ER. The brain and behavior. In: Kandel ER, Schwartz JH, Jessell TM. Principles of neural science. New York: McGraw-Hill, 2000:5-35.

5. Nowakowski RS. Stable neuron numbers from cradle to grave. Proc Natl Acad Sci USA 2006;103(33):12219-12220.

6. Nijhuis JG, editor. Fetal behaviour: developmental and perinatal aspects. Oxford: Oxford University Press, 1992.

7. Okado N, Kakimi S, Kojima T. Synaptogenesis in the cervical cord of the human embryo: sequence of synapse formation in a spinal reflex pathway. J Comp Neurol 1979;184(3):491-518.
8. Okado N, Kojima T. Ontogeny of the central nervous system: neurogenesis, fibre connection, synaptogenesis and myelination in the spinal cord. In: Prechtl HFR, editor. Continuity of neural function from prenatal to postnatal life. Oxford: Blackwell Science, 1984:31-35.

9. Okado N. Onset of synapse formation in the human spinal cord. J Comp Neurol 1981;201(2):211-219.

10. de Vries JIP, Visser GHA, Prechtl HFR. The emergence of fetal behavior I. Qualitative aspects. Early Human Dev 1982; 7(4):301-322.

11. Joseph R. Fetal brain and cognitive development. Dev Rev 1999;20(1):81-98.

12. McCartney G, Hepper P. Development of lateralized behavior in the human fetus from 12 to 27 weeks' gestation. Dev Med Child Neurol 1999;41(2):83-86.

13. Hepper PG, McCartney GR, Shannon EA. Lateralised behavior in first trimester human foetuses. Neuropsychologia 1998;36(6):531-534.

14. Obel C, Hedegaard M, Henriksen TB, Secher NJ, Olsen J. Psychological factors in pregnancy and mixed-handedness in the offspring. Dev Med Child Neurol 2003;45(8):557-561.

15. Triggs WJ, Subramanium B, Rossi F. Hand preference and transcranial magnetic stimulation asymmetry of cortical motor representation. Brain Res 1999;835(2):324-329.

16. Del Guidice M. Fetal programming by maternal stress: Insights from a conflict perspective. Psychoneuroendocrinology 2012; 37(10):1614-1629.

17. Kurjak A, Azumendi G, Vecek N, et al. Fetal hand movements and facial expression in normal pregnancy studied by fourdimensional sonography. J Perinat Med 2003;31(6):496-508.

18. Pooh RK, Ogura T. Normal and abnormal fetal hand positioning and movement in early pregnancy detected by three and four-dimensional ultrasound. Ultrasound Rev Obstet Gynecol 2004;4(1):46-51.

19. Kurjak A, Andonotopo W, Hafner T, et al. Normal standards for fetal neurobehavioral developments-longitudinal quantification by four-dimensional sonography. J Perinat Med 2006;34(1):56-65.

20. Andonotopo W, Medic M, Salihagic-Kadic A, et al. The assessment of fetal behavior in early pregnancy: comparison between $2 \mathrm{D}$ and $4 \mathrm{D}$ sonographic scanning. J Perinat Med 2005;33(5):406-414.

21. Klimach VJ, Cooke RW. Maturation of the neonatal somatosensory evoked response in preterm infants. Dev Med Child Neurol 1988;30(2):208-214.

22. Kostovic I, Judas M, Petanjek Z, Simic G. Ontogenesis of goaldirected behavior: anatomo-functional considerations. Int J Psychophysiol 1995;19(2):85-102.

23. Kostovic I, Judas M, Rados M, Hrabac P. Laminar organization of the human fetal cerebrum revealed by histochemical markers and magnetic resonance imaging. Cereb Cortex 2002;12(5): 536-544.

24. Groome LJ, Swiber MJ, Atterbury JL, et al. Similarities and differences in behavioral state organization during sleep periods in the perinatal infant before and after birth. Child Dev 1997;68(1):1-11.

25. Maccari S, Darnaudery M, Morley-Fletcher S, Zuena AR, Cinque C, Van Reeth O. Prenatal stress and long-term consequences: implications of glucocorticoid hormones. Neurosci Biobehav Rev 2003;27(1-2):119-127.

26. Stanojevic M, Kurjak A, Salihagic-Kadic A, et al. Neurobehavioral continuity from fetus to neonate. J Perinat Med 2011;39(2):171-177. 
27. Kurjak A, Stanojevic M, Andonotopo W, et al. Behavioral pattern continuity from prenatal to postnatal life-a study by four-dimensional (4D) ultrasonography. J Perinat Med 2004;32(4):346-353.

28. Kurjak A, Miskovic B, Stanojevic M, Amiel-Tison C, Ahmed B, Azumendi G, Vasilj O, Andonotopo W, Turudic T, SalihagicKadic A. New scoring system for fetal neurobehavior assessed by three- and four-dimensional sonography. J Perinat Med 2008;36(1):73-81.

29. Predojević M, Talić A, Stanojević M, Kurjak A, Salihagić Kadić A. Assessment of motoric and hemodynamic parameters in growth restricted fetuses-case study. J Matern Fetal Neonatal Med 2014;27(3):247-251.

30. Petrikovsky R, Kaplan G, Holsten N. Fetal yawning acitivty in high risk fetuses: a preliminary observation. Ultrasound Obstet Gynecol 1999;13(2):127-130.

31. Ross MG, El Haddad M, DeSai M. Unopposed orexic pathways in the developing fetus. Physiol Behav 2003;79 (1):79-88.

32. Diamant NE. Development of esophageal function. Am Rev Respir Dis 1985;131(5):S29-S32.

33. Ross MG, Nijland JM. Development of ingestive behavior. Am J Physiol 1998;274(4 pt 2):R879-893.

34. Molliver ME, Kostovic I, Van der Loos H. The development of synapses in cerebral cortex of the human fetus. Brain Res 1973;50(2):403-407.

35. Fitzgerald M. Development of pain mechanisms. Br Med Bul 1991;47(3):667-675.

36. Smith RP, Gitau R, Glover V, et al. Pain and stress in the human fetus. Eur J Obstet Gynecol Reprod Biol 2000;92(1):161-165.

37. Giannakoulopoulos X, Sepulveda W, Kourtis P, et al. Fetal plasma cortisol and beta endorphin response to intrauterine needling. Lancet 1994;344(8915):77-81.

38. Giannakoulopolous X, Teixeira J, Fisk N, et al. Human fetal and maternal noradernaline responses to invasive procedures. Pediatr Res 1999;45(4 pt 1):494-499.

39. Stevens BJ, Johnston CC, Grunau RVE. Issues of assessment of pain and discomfort in neonates. J Obstet Gynecol Neonatal Nurs 1995;24(9):849-855.

40. Stevens B, Johnston CC, Petryshen P, Taddio A. The premature infant pain profile. Clin J Pain 1996;12(1):13-22.

41. Anand KJS, Sippell WG, Aynsley-Green A. Randomized trial of fentaniyl anaesthesia in preterm babies undergoing surgery:effects of the stress response. Lancet 1987;1(8524): 62-66.

42. Anand KJS. Clinical importance of pain and stress in preterm neonates. Biol Neonate 1998;73(1):1-9.

43. Uno H, Lohmiller L, Thieme C, et al. Brain damage induced by prenatal exposure to dexamethasone in fetal rhesus macaques. I. Hippocampus. Brain Res Dev Brain Res 1990; 53(2):157-167.

44. Grunau RVE, Whitfield MF, Petrie JH, et al. Early pain experience, child and family factors, as precursors of somatization: a prospective study of extremely premature infants and fulterm children. Pain 1994;56(3):353-359.

45. Taddio A, Katz J, Ilerich Al, et al. Effect of neonatal circumcision on pain response during subsequent routine vaccination. Lancet 1997;349(9052):599-603.

46. Anand KJS, Phil D, Carr DB. The neuroanatomy, neurophysio$\log y$, and neurochemistry of pain, stress, and analgesia in newborns and children. Ped Clin North Am 1989;36(4): 795-822.
47. Hepper P, Shahidullah S. Development of fetal hearing. Arch Dis Child 1994;71(2):81-87.

48. Cowperthwaite B, Hains SM, Kisilevsky BS. Fetal behavior in smoking compared to non-smoking pregnant women. Infant Behav Dev 2007;30(3):422-430.

49. Marshall J.Infant Neurosensory Development:Considerations for Infant Child Care. Early Childhood Education Journal 2011;39(3):1-7.

50. Bradley RM, Mistretta CM. The developing sense of taste. In: Denton VDA and Coghlan JP. Olfaction and Taste. New York: Academic 1975:91-98.

51. Mennella JA, Johnson A, Beauchamp GK. Garlic ingestion by pregnant women alters the odor of amniotic fluid. Chem Senses 1995;20(2):207-209.

52. Adair LS. Child and adolescent obesity: epidemiology and developmental perspectives. Physiol Behav 2008;94(1):8-16.

53. Hohw ü L, Li J, Olsen J, Sørensen TI, Obel C. Severe maternal stress exposure due to bereavement before, during and after pregnancy and risk of overweight and obesity in young adult men: a Danish National Cohort Study. PLoS One 2014; 14;9(5):e97490.

54. Gitau R, Fisk NM, Teixeira JM, Cameron A, Glover V. F et al. hypothalamic-pituitary-adrenal stress responses to invasive procedures are independent of maternal responses. J Clin Endocrinol Metab 2001;86(1):104-109.

55. Sontag LW. The significance of fetal environmental differences. Am J Obstet Gynecol 1941;42(6):996-1003.

56. Thompson WR. Influence of prenatal maternal anxiety on emotionality in young rats. Science 1957;125(3250):698-699.

57. Barbazanges A, Piazza PV, Le Moal M, Maccari S. Maternal glucocorticoid secretion mediates long-term effects of prenatal stress. J Neurosci 1996;16(12):3943-3949.

58. Hayashi A, Nagaoka M, Yamada K, et al. Maternal stress induces synaptic loss and developmental disabilities of offspring. Int J Dev Neurosci 1998;16(3-4):209-216.

59. Rees S, Harding R. Brain development during fetal life: influences of the intra-uterine environment. Neursci Lett 2004;361(1-3):111-114.

60. Hundertmark S, Ragosch V, Zimmermann B, et al. Effect of dexamethasone, triiodothyronine and dimethyl-isopropylthyronine on lung maturation of the fetal rat lung. J Perinat Med 1999;27(4):309-315.

61. Reynolds RM. Glucocorticoid excess and the developmental origins of disease: two decades of testing the hypothesis - 2012. Curt Richter Award Winner. Psychoneuroendocrinology 2013;38(1):1-11.

62. Talge NM, Neal C, Glover V. Antenatal maternal stress and long-term effects on child neurodevelopment: how and why? J Child Psychol Psychiatry 2007;48(3-4):245-261.

63. Wong ML, Licinio J, Pasternak KI, Gold PW. Localization of corticotropin-releasing hormone (CRH) receptor mRNA in adult rat brain by in situ hybridization histochemistry. Endocrinology 1994;135(5):2275-2278.

64. Lombroso PJ, Sapolsky R. Development of the cerebral cortex: XII. Stress and brain development: I. J Am Acad Child Adolesc Psychiatry 1998;37(12):1337-1339.

65. Sandman CA, Wadhwa PD, Chicz-Demet A, et al. Maternal corticotropin-releasing hormone and habituation in human fetus. Dev Psychobiol 1999;34(3):163-173.

66. King BR, Smith R, Nicholson RC. The regulation of human corticotrophin-releasing hormone gene expression in the placenta. Peptides 2001;22(11):1941-1947. 
67. Robinson BG, Emanuel RL, Frim DM, Majzoub JA. Glucocorticoid stimulates expression of corticotropin-releasing hormone gene in human placenta. Proc Natl Acad Sci USA 1988;85(14):5244-5248.

68. Goland RS, Tropper PJ, Warren WB, Stark RI, Jozak SM, Conwell IM. Concentrations of corticotrophin-releasing hormone in the umbilical-cord blood of pregnancies complicated by pre-eclampsia. Reprod Fertil Dev 1995; 7(5):1227-1230.

69. Petraglia F, Aguzzoli L, Florio P, Baumann P, Genazzani $\mathrm{AD}$, Di Carlo C, Romero R. Maternal plasma and placental immunoreactive corticotrophin-releasing factor concentrations in infection-associated term and pre-term delivery. Placenta 1995;16(2):157-164.

70. Wolfe CD, Patel SP, Linton EA, Campbell EA, Anderson J, Dornhorst A, Lowry PJ, Jones MT. Plasma corticotrophinreleasing factor (CRF) in abnormal pregnancy. Br J Obstet Gynaecol 1988;95(10):1003-1006.

71. Shiota K, Kayamura T. Effects of prenatal heat stress on postnatal growth, behavior and learning capacity in mice. Biol Neonate 1989;56(1):6-14.

72. Jonson KM, Lyle JG, Edwards MJ, Penny RH. Effect of prenatal heat stress on brain growth and serial discrimination reversal learning in the guinea pig. Brain Res Bull 1976;1(1):133-150.

73. Dunlop SA, Archer MA, QuinlivanJA, Beazley LD, Newnham JP. Repeated prenatal corticosteroids delay myelination in the ovine central nervous system. J Matern Fetal Med 1997; 6(6):309-313.

74. Quinlivan JA, Beazley LD, Braekevelt CR, Evans SF, Newnham JP, Dunlop SA. Repeated ultrasound guided fetal injections of corticosteroid alter nervous system maturation in the ovine fetus. J Perinat Med 2001;29(2):112-127.

75. Rodriguez JJ, Montaron MF, Petry KG, Aurousseau C, Marinelli M, Premier S, Rougon G, Le Moal M, Abrous DN. Complex regulation of the expression of the polysialylated form of the neuronal cell adhesion molecule by glucocorticoids in the rat hippocampus. Eur J Neurosci 1998;10(9):2994-3006.

76. Schwab M, Antonow-Schlorke I, Kühn B, Müller T, SchubertH, Walter B, Sliwka U, Nathanielsz PW. Effect of antenatal betamethasone treatment on microtubule-associated proteins MAP1B and MAP2 in fetal sheep. J Physiol 2001; 530(Pt 3): 497-506.

77. Uno H, Eisele S, Sakai A, Shelton S, Baker E, DeJesus O, Holden J. Neurotoxicity of glucocorticoids in the primate brain. Horm Behav 1994;28(4):336-348.

78. Schneider ML, Moore CF, Kraemer GW, Roberts AD, DeJesus OT. The impact of prenatal stress, fetal alcohol exposure, or both on development: perspectives from a primate model. Psychoneuroendocrinology 2002;27(1-2):285-298.

79. Clarke AS, Schneider ML. Prenatal stress has long-term effects on behavioral responses to stress in juvenile rhesus monkeys. Dev Psychobiol 1993;26(5):293-304.

80. Schneider ML. Prenatal stress exposure alters postnatal behavioral expression under conditions of novelty challenge in rhesus monkey infants. Dev Psychobiol 1992;25(7):529-540.

81. Amiel-Tison C, Cabrol D, Denver R, Jarreau PH, PapiernikE, Piazza PV. Fetal adaptation to stress: Part II. Evolutionary aspects; stress-induced hippocampal damage; long-term effects on behavior; consequences on adult health. Early Hum Dev 2004;78(2):81-94.

82. Li J, Olsen J, Vestergaard M, Obel C. Attention-deficit/ hyperactivity disorder in the offspring following prenatal maternal bereavement: a nationwide follow-up study in Denmark. Eur Child Adolesc Psychiatry 2010;19(10):747-753.

83. Buitelaar JK, Huizink AC, Mulder EJ, de Medina PG, Visser GH. Prenatal stress and cognitive development and temperament in infants. Neurobiol Aging 2003;24(Suppl1):S53-60.

84. Davis EP, Glynn LM, Schetter CD, Hobel C, Chicz-Demet A, Sandman CA. Prenatal exposure to maternal depression and cortisol influences infant temperament. J Am Acad Child Adolesc Psychiatry 2007;46(6):737-746.

85. Bergman K, Sarkar P, Glover V, O'Connor TG. Maternal prenatal cortisol and infant cognitive development: moderation by infant-mother attachment. Biol Psychiatry 2010; 67(11):1026-1032.

86. Gutteling BM, de Weerth C, Zandbelt N, Mulder EJ, Visser GH, Buitelaar JK. Does maternal prenatal stress adversely affect the child's learning and memory at age six? J Abnorm Child Psychol 2006;34(6):789-798.

87. Laplante DP, Brunet A, Schmitz N, Ciampi A, King S. Project Ice Storm: prenatal maternal stress affects cognitive and linguistic functioning in 51/2-year-old children. J Am Acad Child Adolesc Psychiatry 2008;47(9):1063-1072.

88. Cladji C, Dioro J, Meaney MJ. Variations in maternal care in infancy regulate the development of stress reactivity. Biol Psychiatry 2000;48(12):1164-1174.

89. Francis DD, Diorio J, Plotsky PM, Meaney MJ. Environmental enrichment reverses the effects of maternal separation on stress reactivity. J Neurosci 2002;22(18):7840-7843.

90. Yang J, Hou C, Ma N, et al. Enriched environment treatment restores impaired hippocampal synaptic plasticity and cognitive deficits induced by prenatal chronic stress. Neurobiol Learn Mem 2007;87(2):257-263.

91. Carmichael SL, Shaw GM, Yang W, Abrams B, Lammer EJ. Maternal stressful life events and risks of birth defects. Epidemiology 2007;18(3):356-361.

92. Zhu JL, Olsen J, Sørensen HT, Li J, Nohr EA, Obel C, Vestergaard M, Olsen MS. Prenatal maternal bereavement and congenital heart defects in offspring: a registry-based study. Pediatrics 2013;131(4):e1225-e1230.

93. Li J, Vestergaard M, Obel C, Cnattingus S, Gissler M, Ahrensberg J, Olsen J. Antenatal maternal bereavement and childhood cancer in the offspring: a population-based cohort study in 6 million children. Br J Cancer 2012;107(3):544-548.

94. Barker DJP. Fetal origins of coronary heart disease. BMJ 1995; 311(6998):171-174.

95. Bertram C, Trowern AR, Copin N, Jackson AA, Whorwood $\mathrm{CB}$. The maternal diet during pregnancy programs altered expression of the glucocorticoid receptor and type 211 betahydroxysteroid dehydrogenase: potential molecular mechanisms underlying the programming of hypertension in utero. Endocrinology 2001;142(7):2841-2853.

96. Cottrell EC, Seckl JR. Prenatal stress, glucocorticoids and the programming of adult disease. Front Behav Neurosci 2009; 3(19):1-9.

97. Smythe JW, Rowe WB, Meaney MJ. Neonatal handling alters serotonin (5-HT) turnover and 5-HT2 receptor binding in selected brain regions: relationship to the handling effect on glucocorticoid receptor expression. Brain Res Dev Brain Res 1994;80(1-2):183-189.

98. Cottrell EC, Seckl JR, Holmes MC, Wyrwoll CS. Foetal and placental $11 \beta$-HSD2: a hub for developmental programming. Acta Physiol 2014;210(2):288-295. 
99. Huh SY, Andrew R, Rich-Edwards JW, Kleinman KP, SecklJR, Gillman MW. Association between umbilical cord glucocorticoids and blood pressure at age 3 years. BMC Med 2008;6:25. Available at: http//www.biomedcentral.com/1741-7015/6/25.

100. Clifton VL, Murphy VE. Maternal asthma as a model for examining fetal sex-specific effects on maternal physiology and placental mechanisms that regulate human fetal growth. Placenta 2004(Suppl A):S45-S52.

101. McTernan CL, Draper N, Nicholson H, Chalder SM, Driver P, Hewison M, Kilby MD, Stewart PM. Reduced placental 11 beta-hydroxysteroid dehydrogenase type 2 mRNA levels in human pregnancies complicated by intrauterine growth restriction: an analysis of possible mechanisms. J Clin Endocrinol Metab 2001;86(10):4979-4983.

102. Watson JB, Mednick SA, Huttunen M, Wang X. Prenatal teratogens and the development of adult mental illness. Dev Psychopathol 1999;11(3):457-466.

103. Van Os J, Selten JP. Prenatal exposure to maternal stress and subsequent schizophrenia. The May 1940 invasion of the Netherlands. Br J Psychiatry 1998;172(4):324-326.

104. O'Connor TG, Heron J, Golding J, Beveridge M, Glover V. Maternal antenatal anxiety and children's behavioural/ emotional problems at 4 years. Report from the Avon Longitudinal Study of Parents and Children. Br J Psychiatry 2002;180(6):502-508.

105. Buss C, Davis EP, Shahbaba B, Pruessner JC, Head K, Sandman CA. Maternal cortisol over the course of pregnancy and subsequent child amygdala and hippocampus volumes and affective problems. Proc Natl Acad Sci USA 2012; 109(20):E1312-E1319.

106. Nijland MJ, Ford SP, Nathanielsz PW. Prenatal origins of adult disease. Curr Opin Obstet Gynecol 2008;20(2):132-138.

107. Zambrano E, Martínez-Samayoa PM, Bautista CJ, Deás M, Guillén L, Rodríguez-González GL, Guzmán C, Larrea F, Nathanielsz PW.Sex differences in transgenerational alterations of growth and metabolism in progeny (F2) of female offspring (F1) of rats fed a low protein diet during pregnancy and lactation. J Physiol 2005;566(pt 1):225-236.

108. Aiken CE, Ozanne SE. Sex differences in developmental programming models. Reproduction 2013;145(1):R1-R13.

109. Cuffe JS, Dickinson H, Simmons DG, Moritz KM. Sex specific changes in placental growth and MAPK following short term maternal dexamethasone exposure in the mouse. Placenta 2011;32(12):981-989. 